\title{
Development and evaluation of a TaqMan duplex real-time PCR quantification method for reliable enumeration of Candidatus Microthrix
}

\author{
Louise Vanysacker ${ }^{\text {a, } *}$, Carla Denis ${ }^{b}$, Joris Roels ${ }^{c}$, Kirke Verhaeghe ${ }^{c}$, Ivo F.J. Vankelecom ${ }^{a}$ \\ a Centre for Surface Chemistry and Catalysis, KU Leuven, Kasteelpark Arenberg 23, P.O. Box 2461, 3001 Heverlee, Belgium \\ b Laboratory of Aquatic Ecology and Evolutionary Biology, KU Leuven, Charles Deberiotstraat 32, 3000 Leuven, Belgium \\ ${ }^{\text {c } R e s e a r c h ~ a n d ~ P r o d u c t ~ D e v e l o p m e n t ~ D e p a r t m e n t, ~ A q u a f i n ~ N V, ~ D i j k s t r a a t ~ 8, ~ A a r t s e l a a r ~ 2630, ~ B e l g i u m ~}$
}

\section{A R T I C L E I N F O}

\section{Article history:}

Received 27 May 2013

Received in revised form 21 November 2013

Accepted 21 November 2013

Available online 11 December 2013

\section{Keywords:}

Microthrix parvicella

Microthrix calida

Sludge bulking

Real-time PCR

TaqMan

\begin{abstract}
A B S T R A C T
Candidatus Microtrhix parvicella is one of the most common filamentous bacteria reported to be involved in bulking and foaming problems in activated sludge plants worldwide. In order to detect and quantify both M. parvicella and Microthrix calida by quantitative PCR (qPCR), primers targeting 16S rDNA genes were designed. The qPCR reaction was optimized by using the TaqMan technology and an internal positive control was included to ensure the absence of PCR inhibitors. A total of 29 samples originating from different wastewater treatment plants were analyzed and the results were compared by using conventional microscopy, fluorescent in situ hybridization and an existing SYBR Green-based assay. Our assay showed a $100 \%$ specificity for both M. parvicella and $M$. calida, a sensitivity of $2.93 \times 10^{9}$ to 29 copy numbers/reaction, an amplification efficiency of $93 \%$ and no PCR inhibition. By performing a spiking experiment including different Microthrix concentrations, recovery rates ranging from 65 to $98 \%$ were obtained. A positive correlation with the SYBR Green assay $\left(R^{2}=0.85\right)$ was found and most of the samples were in accordance with the microscopical observation. In comparison with SYBR Green assay, the probe-based TaqMan assay had a much lower detection limit. Compared with microscopy, some samples had a lower or higher enumeration when using qPCR. In conclusion, a qPCR method is forwarded here that could be useful as an early warning tool for fast and reliable detection of Microthrix in for instance sludge bulking events.
\end{abstract}

(c) 2013 Elsevier B.V. All rights reserved.

\section{Introduction}

Good settling properties of activated sludge are crucial for the separation of sludge from treated wastewater. However, an excessive growth of filamentous bacteria in activated sludge wastewater treatment plants (WWTPs) can cause serious operational problems (Martins et al., 2004). An overgrowth of some filaments, an event called sludge bulking, can prevent adequate flocculation and settling of the biomass. Another related problem caused by bacterial filaments is foaming, which is referring to the formation of a stable, viscous, chocolate-colored scum layer on the surface of aeration basins and secondary clarifiers (Jenkins et al., 2004). Flocs containing too many filaments are less compact and have poor settling properties. Stable foam is formed as a result of high amounts of filaments with a hydrophobic cell surface. The flocs formed by these microorganisms tend to attach to air bubbles and float on the surface of the sludge basin. Bulking and foaming sludge can therefore give rise to operational difficulties (Daims et al., 2006).

More than 30 different filament morphotypes have been described in activated sludge systems treating primarily municipal wastewater

\footnotetext{
* Corresponding author. Tel.: + 32 16377953; fax: + 3216321998.

E-mail address: louise.vanysacker@biw.kuleuven.be (L. Vanysacker).
}

(Eikelboom, 1975, 2000) and many more are encountered in industrial treatment plant communities (Eikelboom, 2006; Eikelboom and Geurkink, 2002). Several global surveys have shown that Candidatus Microthrix parvicella (hereinafter referred to as M. parvicella) is most frequently responsible for the problems of solid-liquid separation in bulking and foaming (Jenkins et al., 2004; Martins et al., 2004; Wanner, 1994).

M. parvicella is a long, thin (diameter of 0.6-0.8 $\mu \mathrm{m}$ ), non-branched and unsheathed filamentous bacterium. Its coiled appearance and characteristic Gram-positive reaction makes it possible to be recognized by microscopy (Rossetti et al., 1997). Recently, another Microthrix species, M. calida, was isolated from industrial activated sludge samples (Levantesi et al., 2006). This filament appears as a thinner version of M. parvicella, with 95.7-96.7\% shared sequence similarity. Although there are no in situ ecophysiological studies available on M. calida, it is suggested that a similar behavior could be expected in pure culture and in activated sludge (Levantesi et al., 2006).

Although M. parvicella is infamous for causing sludge bulking and foaming, up to now it has only been detected in activated sludge systems. Some isolates have been cultured (Blackall et al., 1995, 1996; Eikelboom, 1975; Rossetti et al., 1997; Seviour et al., 1994; Slijkhuis, 1983a, 1983b; Tandoi et al., 1998; Van Veen, 1973) and only a few of them are maintained in pure culture (Blackall et al., 1995; Rossetti 
et al., 1997; Seviour et al., 1994). Its slow growth rate and difficulty in storing isolates and in generating phenotypic information have hindered attempts to elucidate the reasons for the proliferation of $M$. parvicella in WWTPs. Up to now the abundance of these bacteria is determined subjectively by observing Gram- and Neisser-stained filaments (Eikelboom and van Buijsen, 1983) or by in situ hybridization with probes targeting the 16S rDNA (Erhart et al., 1997). The first method is considered to be feasible, but requires experienced staff because of morphological variability resulting from different growth conditions (de los Reyes et al., 2002; Roels et al., 2002; Westlund et al., 1998). Yet, under those conditions a reliable identification of M. parvicella is possible. Low rDNA levels, because of low metabolic activity of bacteria, and a possible incomplete permeability of the cell wall for the probe can result in poor quantification of M. parvicella by in situ hybridization (Bradford et al., 1998; Oerther et al., 2001). A more exact quantification using quantitative PCR or qPCR (often referred to as real-time PCR) using the SYBR chemistry has recently been published (Kaetzke et al., 2005).

SYBR Green binds to all double-stranded DNA, which makes it very sensitive in the detection of nonspecific products and thus an overestimation of the target DNA. On the other hand, the TaqMan chemistry has an additional specificity as it utilizes a fluorescently labeled probe (Livak et al., 1995). In addition the use of different fluorophores enables the development of multiplex qPCR protocols whereby different targets can be co-amplified and quantified within one single reaction (Baldwin et al., 2003, 2008; Neretin et al., 2003). An example of the latter is the use of an exogenous internal positive control (IPC) (Hartman et al., 2005). In contrast to an internal inhibitor control, an IPC amplifies under the same PCR conditions as the target DNA, but using its own primer and probe sets (Hartman et al., 2005; Welti et al., 2003). PCR inhibitors have been a persistent problem when working with DNA from environmental samples. The quality of the DNA extracted from environmental samples is a limiting factor when using molecular approaches. Contaminants as such are usually inhibiting molecules that co-extract with nucleic acids (Vanysacker et al., 2010). This is particularly true when working with highly sensitive enzymatic reactions such as qPCR for which, in addition to the usual inhibition of the enzymatic reaction, environmental contaminants can also interfere with the detection method based on fluorescence (Radstrom et al., 2004; Stults et al., 2001; Wilson, 1997).

The aim of this paper was to develop a TaqMan assay for the simultaneous detection of M. parvicella-M. calida and PCR inhibitors. The sensitivity and specificity were evaluated and a comparison with microscopical observations and a previously published SYBR Green qPCR assay (Kaetzke et al., 2005) is discussed.

\section{Materials and methods}

\subsection{Sampling and DNA extraction}

Approximately $100 \mathrm{ml}$ of activated sludge samples was taken from 29 WWTPs. Fresh samples were directly observed by microscopy and $500 \mu \mathrm{l}$ was extracted using Mobio Ultraclean ${ }^{\mathrm{TM}}$ soil DNA kit (Cambio). In order to avoid intraspecific sample variation, each sample was extracted 4 times. Afterwards the eluted DNA was mixed together, divided in aliquot parts and stored at $-20{ }^{\circ} \mathrm{C}$ until further use.

\subsection{Microscopy}

\subsubsection{Morphological characterization}

Sludge floc size and filamentous bacteria assessment were monitored by phase contrast (wet preparation) and bright field (stained preparation) microscopy using different magnifications $(100 \times, 200 \times$, $400 \times$ and $1000 \times)$ (Olympus BX51).

The filamentous bacteria present in WWTP were morphologically identified and the filament characteristics were determined using the
Eikelboom's classification system (Table 1) (Eikelboom and Geurkink, 2000; Eikelboom and van Buijsen, 1983). Referring to morphological and color characteristics of the filaments (Jenkins et al., 2004), the Gram staining and Neisser staining were respectively performed as described by Adamse (1970) and Gurr (1965). The morphological characterization and quantification were performed at the laboratory of Aquafin N.V. The laboratory is accredited by the Belgian Accreditation Body as a testing laboratory, according to the requirements of NBN EN ISO/IEC 17025:2005 for the determination of filamentous bacteria in wastewater samples. The filament abundances were categorized in 4 groups: low, moderately, highly and very highly concentrated.

\subsubsection{Fluorescence in situ hybridization}

Fluorescence in situ hybridization (FISH) was performed according to a protocol slightly adapted from Nielsen (2009). The EUB338 probe was used for the hybridization of all bacteria (Amann et al., 1990) and the MPA-MIX probe for M. parvicella and M. calida (Erhart et al., 1997) (Table 2). Slides were mounted in Citifluor (Citifluor Ltd.) and visualized with a BX51 epifluorescence microscope (Olympus) equipped with a UPlanApo 100x/1.35 oil objective, U-M51009 filterset and Cell P software (Olympus).

\subsection{Design of oligonucleotides, DNA cloning and sequencing}

For the TaqMan assay, a new primer-probe set for the quantification of $M$. parvicella $16 \mathrm{~S}$ rRNA gene was designed, relying on an alignment of different M. parvicella 16S rRNA sequences (accession numbers X89774, X89561, X89560 and X82546) (Table 2). Primers were designed using Primer Express version 2.0 (Applied Biosystems, Foster City, CA) following the user manufacturer guidelines for the design of MGB probes. To confirm the specificity of the primers and probes, the PCR product was cloned using the TOPO ${ }^{\circ}$ TA Cloning $®$ Kit (Invitrogen) and blasted against the non-redundant GenBank database (http:// blast.ncbi.nlm.nih.gov). Clones were generated by inserting the PCR products, derived from the new designed primer pair and activated sludge samples as template, together with the $\mathrm{PCR}^{\mathrm{TM}} 2.1-\mathrm{TOPO} \otimes$ vector into One Shot ${ }^{\circledR}$ Escherichia coli cells according to the manufacturer's instructions. Colonies that contained a plasmid with an insert were screened on Lysogeny Broth agar plates supplemented with ampicillin (50 $\mu \mathrm{g} / \mathrm{ml}$, Sigma-Aldrich). Positive colonies were selected and controlled by PCR. The PCR mixture contained $1 \mu \mathrm{l}$ of DNA, $1 \mu \mathrm{MgCl}_{2}$ (50 mM), $2.5 \mu \mathrm{l}$ of $10 \times$ reaction buffer (Invitrogen), dNTPs $(2 \mathrm{mM})$, $0.1 \mu \mathrm{laq}$ polymerase $(2.5 \mathrm{U}$ ) and $1 \mu \mathrm{l}$ of M13 forward (5'-GTAAAACG ACGGCCAG-3') and reverse (5'-CAGGAAACAGCTATGAC-3') primers (20 mM). PCR fragments of successfully cloned vectors were collected, purified using Illustra GFX ${ }^{\mathrm{TM}}$ PCR DNA and Gel Band Purification kit (GE Healthcare), and sequenced using the BigDye Terminator Sequencing kit v3.1 (Applied Biosystems). The sequencing reaction was performed with M13 forward and reverse primers separately. Thermal cycle conditions were: initial denaturation at $95{ }^{\circ} \mathrm{C}$ for $1 \mathrm{~min}$, followed by 25 cycles of $95{ }^{\circ} \mathrm{C}$ for $10 \mathrm{~s}, 50{ }^{\circ} \mathrm{C}$ for $10 \mathrm{~s}$, and $60{ }^{\circ} \mathrm{C}$ for $4 \mathrm{~min}$. The resulting products were sequenced by capillary electrophoresis on an ABI Prism 3130-Genetic Analyzer (Applied Biosystems) using POP7 polymer. Consensus sequences as determined with accompanying software (SeqScape v2.5) were aligned using BioEcovit v7.1.9.

\subsection{Preparation of the calibration standards}

Since no pure culture of $M$. parvicella was available, a calibration standard was constructed using amplified PCR-fragments. The most convenient way to create a DNA standard is to clone a PCR product into a standard vector. Advantages of this method are: large amounts of standard can easily be produced, the ability of species identification by sequencing, and the possibility of DNA quantification by spectrophotometry. The previously described clones (Section 2.3.), where after the M13 PCR and the purification step, were quantified using Quant-iT ${ }^{\mathrm{TM}}$ 
Table 1

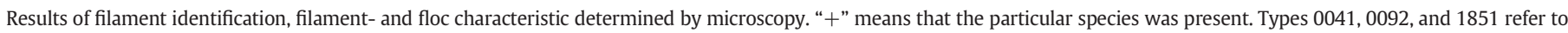
Eikelboom's types 0041/0675, 0092 and 1851 respectively. The parameters were evaluated using Eikelboom's classification system (17, 32).

\begin{tabular}{|c|c|c|c|c|c|c|c|c|c|c|}
\hline \multirow[t]{2}{*}{ Sample number } & \multicolumn{6}{|c|}{ Filament identification } & \multicolumn{2}{|c|}{ Filament characteristic } & \multicolumn{2}{|c|}{ Floc characteristic } \\
\hline & M. parvicella & Type 0041 & Type 0092 & Nocardia spp. & Nostocoida limocola & Type 1851 & Abundance & Effect on floc structure & Shape & Structure \\
\hline 1 & + & & & & & & Very high & Cluster-cluster aggregation & Irregular & Diffuse \\
\hline 2 & + & + & & & & & High & Bridging & Irregular & Diffuse \\
\hline 3 & + & + & & + & & & High & Open floc structure & Irregular & Diffuse \\
\hline 4 & + & & & & + & + & High & Bridging & Irregular & Diffuse \\
\hline 5 & + & + & & & & & High & Cluster-cluster aggregation & Irregular & Compact \\
\hline 6 & & + & & & & & High & Open floc structure & Irregular & Diffuse \\
\hline 7 & + & + & & & & & High & Bridging & Agglomerates & Diffuse \\
\hline 8 & + & + & & & & & High & Open floc structure & Irregular & Diffuse \\
\hline 9 & & & & & & & Moderate & Little or none & Round & Compact \\
\hline 10 & + & + & & & & & High & Open floc structure & Agglomerates & Diffuse \\
\hline 11 & + & + & & & & & High & Cluster-cluster aggregation & Irregular & Diffuse \\
\hline 12 & + & + & & & & & Moderate & Open floc structure & Irregular & Diffuse \\
\hline 13 & + & & & & & & High & Cluster-cluster aggregation & Irregular & Diffuse \\
\hline 14 & + & + & & & & & High & Open floc structure & Irregular & Diffuse \\
\hline 15 & + & + & & & & & High & Open floc structure & Irregular & Diffuse \\
\hline 16 & + & + & & & & & Moderate & Little or none & Irregular & Diffuse \\
\hline 17 & & & & & & & Moderate & Open floc structure & Irregular & Diffuse \\
\hline 18 & + & + & & & & & High & Cluster-cluster aggregation & Round & Compact \\
\hline 19 & + & + & & & & & Moderate & Open floc structure & Irregular & Diffuse \\
\hline 20 & + & & & & & & Very high & Cluster-cluster aggregation & Irregular & Diffuse \\
\hline 21 & + & + & & & & & High & Bridging & Agglomerates & Diffuse \\
\hline 22 & + & & & & & & Very high & Bridging & Agglomerates & Diffuse \\
\hline 23 & + & + & + & & & & Very high & Cluster-cluster aggregation & Agglomerates & Diffuse \\
\hline 24 & & & & & & & Moderate & Open floc structure & Irregular & Diffuse \\
\hline 25 & + & + & & + & & & High & Cluster-cluster aggregation & Round & Compact \\
\hline 26 & + & & & + & & & Moderate & Open floc structure & Irregular & Diffuse \\
\hline 27 & M. parvicella & + calida & + & & & & High & Open floc structure & Irregular & Diffuse \\
\hline 28 & + & + & + & & + & & High & Little or none & Round & Compact \\
\hline 29 & + & + & + & & & & High & Cluster-cluster aggregation & Irregular & Diffuse \\
\hline
\end{tabular}

PicoGreen ${ }^{\circledR}$ dsDNA Assay Kit (Invitrogen). The exact amount of DNA was calculated as follows: $(\mathrm{X}(\mathrm{g} / \mathrm{\mu l} \mathrm{DNA}) /[$ plasmid lenght in $\mathrm{bp} \times$ $660]) \times\left(6.02 \times 10^{23}\right)=\mathrm{Y}$ amplicon/ $/$ l. Based on the assumptions that the average 16S rDNA gene copy number is 3.05 for the Actinobacteria related species, the relative abundance of Microthrix cells was recalculated (rrndb release 3.1.221 Klappenbach et al., 2001).

\subsection{Quantitative PCR}

\subsubsection{Optimization reactions}

First, the qPCR protocol was optimized using different probe types, primer concentrations, and $\mathrm{MM}(\mathrm{MM})$ reagents.

Considering the probe design, a Minor Groove Binding (MGB) and a TAMRA probe with slightly different sequences were compared. The TAMRA probe contained a 6-carboxy-tetramethyl-rhodamine quencher molecule and a longer sequence length (23 bp). The MGB probe was shorter (16 bp) and contained a non-fluorescent quencher.

Secondly, the optimal primer concentrations were determined in separate tubes by running a matrix of five different forward and reverse primer concentrations (500, 250, 100, 75 and $10 \mathrm{nM}$ ) according to the Application note of Applied Biosystems (136AP04-01; http://www. appliedbiosystems.com).

Finally, three types of MM were tested: TaqMan ${ }^{\circ}$ Gene expression MM (P/N 4369016, Applied Biosystem, CA, USA), TaqMan ${ }^{\circledR}$ Fast Advanced MM (P/N 4444557 Applied Biosystem, California, USA) and qPCR MM Plus (P/N 05-QP2X-03-075, Eurogentec, Seraing, Belgium). The MM was evaluated in terms of amplification efficiencies and background noise in the non-template control.

\subsection{2. $q P C R$ reaction}

DNA amplification and PCR product detection were performed using the ABI Prism ${ }^{\circledR} 7000$ Sequence Detection System (Applied Biosystems). The amplification efficiencies were evaluated using a TaqMan® Exogenous Internal Positive Control (IPC) (Applied Biosystems) (Hartman et al., 2005). Each sludge sample was assayed together with their 10fold dilution in triplo. A $25 \mu \mathrm{l}$ qPCR reaction containing $2.5 \mu \mathrm{l}$ of template DNA, $12.5 \mu \mathrm{l}$ of $2 \times$ qPCR MM Plus (Eurogentec), $75 \mathrm{nM}$ of forward and reverse primers and $0.2 \mu \mathrm{M}$ of the MGB labeled probe

Table 2

Primers and probes used in this study.

\begin{tabular}{|c|c|c|c|c|c|c|}
\hline Target group & Use & Type & Dye & Name & $5^{\prime}$ to $3^{\prime}$ sequence & Reference \\
\hline \multirow[t]{5}{*}{ Bacteria } & \multirow[t]{4}{*}{ qPCR } & Forward primer & & BACT1369F & CGGTGAATACGTTCYCGG & \multirow[t]{4}{*}{ Suzuki et al. (2000) } \\
\hline & & Reverse primer & & PROK1541R & AAGGAGGTGATCCRGCCGCA & \\
\hline & & MGB probe & FAM $^{\mathrm{TM}}$ & TM1389F & CTTGTACACACCG GCTGCCTC & \\
\hline & & & & & CCGTAGGAGTCCCGTC & \\
\hline & FISH & FISH Probe & Су3 & EUB338 & GCTGCCTCCCGTAGGAGT & Amann et al. (1990) \\
\hline \multirow[t]{2}{*}{ M. parvicella } & \multirow[t]{2}{*}{ qPCR } & Forward primer & & S-S-M.par-0828-S-21 & GGTGTGGGGAGAACTCAACTC & \multirow[t]{2}{*}{ Kaetzke et al. (2005) } \\
\hline & & Reverse primer & & S-S-M.par-1018-A-17 & GACCCCGAAGGACACCG & \\
\hline \multirow{6}{*}{ M. parvicella and M. calida } & \multirow{3}{*}{ qPCR } & Forward primer & & S-G-Mtx-0939-a-S-20 & GCAACGCGAAGAACCTTACC & \multirow[t]{3}{*}{ This study } \\
\hline & & Reverse primer & & S-G-Mtx-1012-a-A-19 & AGCCATGCACCACCTATCG & \\
\hline & & $\mathrm{MGB}^{\mathrm{TM}}$ probe & FAM $^{\mathrm{TM}}$ & S-G-Mtx-0985-a-S-16 & CAGAGATGCGGTGTCC & \\
\hline & \multirow[t]{3}{*}{ FISH } & \multirow[t]{3}{*}{ FISH probe } & \multirow[t]{3}{*}{ FITC } & \multirow[t]{3}{*}{ MPA-MIX (MPA60 + MPA223 + MPA645) } & GGATGGCCGCGTTCGACT & \multirow[t]{3}{*}{ Erhart et al. (1997) } \\
\hline & & & & & GCCGCGAGACCCTCCTAG & \\
\hline & & & & & CCGGACTCTAGTCAGAGC & \\
\hline
\end{tabular}


(Applied Biosystems) (Table 2). The IPC was co-amplified in each PCR reaction, according to the manufacturer's instructions. Double distilled water was used as a negative control. The cycle program was: 2 min at $50{ }^{\circ} \mathrm{C}, 10 \mathrm{~min}$ at $95{ }^{\circ} \mathrm{C}$, and followed by 50 cycles of $15 \mathrm{~s}$ at $95{ }^{\circ} \mathrm{C}$ and $1 \mathrm{~min}$ at $60{ }^{\circ} \mathrm{C}$. The standard curve was automatically generated by the ABI Prism system by plotting the cycle threshold $\left(C_{t}\right)$, at which the threshold fluorescence was reached, versus the logarithmic concentration of positive control DNA. The $C_{t}$ is defined as the number of cycles required for the fluorescent signal of the target DNA to cross the threshold (i.e. exceeds background signal). $C_{t}$ levels are inversely proportional to the amount of target nucleic acid in the sample. Efficiencies were calculated from the equation $E=\left[\left(10^{-1 / \text { slope }}\right) / 2\right] \times 100 \%$ (using the slope of the serial dilution's standard curve). qPCR data analysis was performed with the SDS 1.2.3. software (Applied Biosystems). PCR inhibition was determined by comparing the amplification plot of the IPC of the samples with the amplification plot of the IPC of the positive control DNA. As previously mentioned, IPC amplifies under the same PCR conditions as the target DNA but by using its own primer and probe sets (Hartman et al., 2005), meaning that the target DNA amplification efficiency will never be affected by competition of both IPC and target DNA for the same primer and probe sets. As PCR inhibition mostly concerns inhibition of the DNA polymerase (Stark et al., 2000), the IPC and the target DNA are exposed to the same degree of amplification inhibition. For the enumeration of the entire bacterial population, universal primer and probe targeting highly conserved regions of the $16 \mathrm{~S}$ rDNA gene were used (Table 2). The results of the new developed TaqMan assay were compared with a published SYBR Green assay for the specific detection of M. parvicella (Kaetzke et al., 2005). Amplification reactions were performed, as described by Suzuki et al. (2000) and Kaetzke et al. (2005) respectively.

\section{6. $q P C R$ recovery rates}

To determine whether a known quantity of added DNA can be successfully assayed against a background of other DNA from a range of other organisms a "spiking experiment" was performed. For this purpose three samples were evaluated by microscopy and scored as low, moderately or highly concentrated with Microthrix. After the DNA was extracted and spiked with four different concentrations of clonal Microthrix DNA. The spiked samples were then quantified by qPCR and recovery rates were calculated.

\subsection{Determination of PCR inhibition by polyaluminium chloride}

Polyaluminium chloride (PAX) treatments have been proved to be an effective measure to suppress Microthrix growth in WWTP (Nielsen et al., 2005; Paris et al., 2005). To exclude possible PCR inhibition by $\mathrm{PAX}$, an additional inhibition experiment was performed using different
PAX-14 concentrations. Briefly, 0, 150, 250, 500, 800 and $1000 \mu \mathrm{l} / \mathrm{l}$ (i.e. respectively $0,7,12,23.5,37.6$ and $47 \mathrm{~g} \mathrm{Al}^{3+} / \mathrm{kg}$ MLSS) PAX-14 was added to 6 randomly chosen activated sludge samples. Two experimental conditions were tested: the samples were mixed and incubated 15 min or $2 \mathrm{~h}$. Subsequently, the DNA of $500 \mu \mathrm{l}$ of homogenized sludge was extracted and further analyzed by TaqMan qPCR.

\subsection{Data analysis}

The data from the optimization experiments were compared using one-way analysis of variance (ANOVA) test (Statistica 11.0).

\section{Results and discussion}

\subsection{Determination of the TaqMan assay specificity and optimization}

In order to determine the specificity of the new developed primers, the generated PCR product was sequenced and verified on NCBI (http:// blast.ncbi.nlm.nih.gov). The most relevant results are shown in Table 3. Our assay shows a $100 \%$ specificity for both M. parvicella and M. calida. Sequences of accession numbers DQ147284.1 and DQ147282.1 showed respectively one gap and one insert in their original sequence. For another sequence (accession number X89560.1) 98\% similarity was found due to two unspecified basepairs within the original sequence. Compared to the assay developed by Kaetzke et al. (2005), M. calida has been included in the TaqMan assay, as it is difficult to make a distinction between the two related species. Only slightly thinner filaments and a weaker reaction to Gram-staining characterized the latter (Fig. 4). The comparison between qPCR and microscopy is described in detail in Section 3.3. As the TaqMan assay was developed for both M. parvicella and M. calida, from now on the term "Microthrix" will be used to specify the detection of both morphotypes.

The qPCR protocol was optimized using different probe types, primer concentrations, and MM reagents. In comparison with the MGB assay, the TAMRA probe had a lower PCR efficiency (89.21 vs 93.86\%) (Fig. 1). Moreover, the background signal emitted from the quencher molecule of the TAMRA assay makes low concentrated samples difficult to quantify. Such a signal contamination was noticed at 30 and 34 cycle times for the TAMRA and the MGB assay respectively. The background component of the no template control (NTC) was mathematically removed by the software algorithm of the real-time cycler. The discussed results below are based on the MGB assay.

Five different primer concentrations were tested on Microthrix clonal DNA and DNA extracted from activated sludge samples. The optimal primer concentration was $75 \mathrm{nM}$ as higher concentration $(500,250$, $100 \mathrm{nM}$ ) had similar $C_{\mathrm{t}}$ values and lower concentration (10 nM) results in a weak signal and lower $C_{t}$ values.

Table 3

Most relevant NCBI accession numbers, names and relevant parameters after BLAST of sequenced PCR product using the new developed TaqMan primers and probes.

\begin{tabular}{|c|c|c|c|c|c|c|}
\hline Accession & Name & $\%$ identity & Mismatches & Gap opens & E-value & Bit score \\
\hline DQ147281.1 & Candidatus Microthrix calida strain TN01-1 16S ribosomal RNA gene & 100 & 0 & 0 & $3.00 \mathrm{E}-40$ & 171 \\
\hline DQ147277.1 & Candidatus Microthrix calida strain TNO2-1 16S ribosomal RNA gene & 100 & 0 & 0 & $3.00 \mathrm{E}-40$ & 171 \\
\hline DQ147283.1 & Candidatus Microthrix calida strain TNO2-3 16S ribosomal RNA gene & 100 & 0 & 0 & $3.00 \mathrm{E}-40$ & 171 \\
\hline DQ147284.1 & Candidatus Microthrix calida strain TNO2-4 16S ribosomal RNA gene & 99 & 0 & 1 & $5.00 \mathrm{E}-38$ & 163 \\
\hline FJ638889.1 & Candidatus Microthrix parvicella clone M2 16S ribosomal RNA gene & 100 & 0 & 0 & $3.00 \mathrm{E}-40$ & 171 \\
\hline JQ624332.1 & Candidatus Microthrix parvicella clone OTU-5-40m.ABB $16 \mathrm{~S}$ ribosomal & 100 & 0 & 0 & $3.00 \mathrm{E}-40$ & 171 \\
\hline DQ147278.1 & Candidatus Microthrix parvicella strain BIO17-1 16S ribosomal RNA & 100 & 0 & 0 & $3.00 \mathrm{E}-40$ & 171 \\
\hline DQ147279.1 & Candidatus Microthrix parvicella strain BIO17-2 16S ribosomal RNA & 100 & 0 & 0 & $3.00 \mathrm{E}-40$ & 171 \\
\hline DQ147282.1 & Candidatus Microthrix parvicella strain BIO17-3 16S ribosomal RNA & 99 & 0 & 1 & $1.00 \mathrm{E}-38$ & 165 \\
\hline DQ147280.1 & Candidatus Microthrix parvicella strain EU18 16S ribosomal RNA & 100 & 0 & 0 & $3.00 \mathrm{E}-40$ & 171 \\
\hline X93044.1 & M. parvicella $16 \mathrm{~S}$ ribosomal RNA. & 100 & 0 & 0 & $3.00 \mathrm{E}-40$ & 171 \\
\hline X82546.1 & M. parvicella $16 \mathrm{~S}$ rDNA gene. & 100 & 0 & 0 & $3.00 \mathrm{E}-40$ & 171 \\
\hline X89561.1 & M. parvicella DNA for $16 \mathrm{~S}$ ribosomal RNA gene (clone 17). & 100 & 0 & 0 & $3.00 \mathrm{E}-40$ & 171 \\
\hline X89560.1 & M. parvicella DNA for $16 \mathrm{~S}$ ribosomal RNA gene (clone 6). & 98 & 2 & 0 & $5.00 \mathrm{E}-38$ & 163 \\
\hline X89774.1 & M. parvicella DNA for $16 \mathrm{~S}$ ribosomal RNA gene. & 100 & 0 & 0 & $3.00 \mathrm{E}-40$ & 171 \\
\hline
\end{tabular}




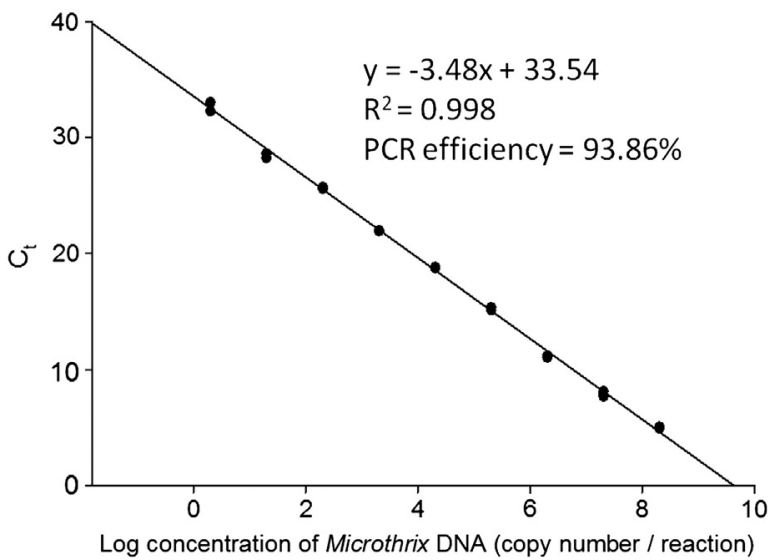

Fig. 1. Serial 10-fold dilution from $2.93 \times 10^{9}$ to 29 copy numbers/qPCR reaction of Microthrix DNA. The standard curve was generated by a linear regression of the threshold cycle $\left(C_{t}\right)$ versus the logarithm of the Microthrix DNA concentration per qPCR reaction.

Considering the MM type, no significant differences in PCR efficiencies were found $(p=0.64)$. On the other hand significantly lower NTC was found using the MM Plus $\left(C_{t} 36.35 \pm 1.72\right)$ compared to the gene expression $\left(C_{t} 34.24 \pm 1.20\right)$ and fast advanced MM $\left(C_{t} 31.62 \pm 0.08\right)$ $(p=0.008)$. Although higher NTC values were found using the $16 \mathrm{~S}$ rDNA assay (ranging from 23.74 to 28.95), no significant differences were found between the tested MM ( $p=0.14)$. The MM effect was more pronounced in the total bacteria 16S rDNA assay. Including the consideration of the price of each TaqMan qPCR run, being respectively 2.14, 2.58 and 1.48 Euro per run for the MM Plus, the TaqMan ${ }^{\circledR}$ Gene Expression Master Mix and the TaqMan ${ }^{\circledR}$ Fast Advanced Master Mix, the MM Plus has been selected based on the observation of lower NTC values and equal PCR efficiencies compared to the other MM types.

\subsection{Determination of the TaqMan assay sensitivity}

Plasmids containing cloned Microthrix 16S rDNA were used to generate a standard curve relating $C_{t}$ to the number of gene copies. Serial 10 -fold dilutions ranging from $2.93 \times 10^{8}$ to 29 copy numbers/qPCR reaction, which is equivalent to $4.15 \times 10^{4}$ fg to $4.15 \times 10^{-3}$ fg DNA, were amplified (Fig. 1). To determine the precision of the TaqMan assay, $C_{t}$ values for five replicates of tenfold dilutions of cloned Microthrix 16S rDNA were measured (Table 4). The results represent independent dilution series and different PCR runs. The mean $C_{t}$ values, standard deviation, and percent CV (coefficient of variation) were calculated for each dilution. The results showed low variability, with CVs ranging from 0.23 to $2.85 \%$.

To determine the assay sensitivity, a 'spiking experiment' was conducted and qPCR recovery rates were measured (Table 5). The qPCR was not able to recover $100 \%$ of the Microthrix DNA. The mean recovery rate was $81.45 \pm 10.31 \%$ (ranging from 66 to 98\%). Every sample type

Table 4

Summary of five different PCR runs performed on eight separate DNA dilution series of Microthrix 16S rDNA

\begin{tabular}{lcll}
\hline Number of copies/PCR reaction & Mean $C_{t}$ & SD $^{\mathrm{a}}$ & $\mathrm{CV}^{\mathrm{b}}(\%)$ \\
\hline $2.93 \times 10^{8}$ & 4.99 & 0.068 & 1.36 \\
$2.93 \times 10^{7}$ & 7.88 & 0.224 & 2.85 \\
$2.93 \times 10^{6}$ & 11.15 & 0.089 & 0.80 \\
$2.93 \times 10^{5}$ & 15.26 & 0.128 & 0.84 \\
$2.93 \times 10^{4}$ & 18.77 & 0.051 & 0.28 \\
$2.93 \times 10^{3}$ & 21.96 & 0.049 & 0.23 \\
$2.93 \times 10^{2}$ & 25.64 & 0.113 & 0.44 \\
$2.93 \times 10^{1}$ & 28.42 & 0.275 & 0.97 \\
\hline
\end{tabular}

a SD: standard deviation of five replicates.

b $\mathrm{CV}$ : coefficient of variation.
Table 5

Results of spiking experiments. BD: below detection limit, '/' means that no spiked DNA was added.

\begin{tabular}{|c|c|c|c|c|}
\hline Sample type & $\begin{array}{l}\text { Spiked } \\
\text { amount }\end{array}$ & Obtained value & $\begin{array}{l}\text { Expected } \\
\text { value }\end{array}$ & Recovery \\
\hline \multicolumn{5}{|c|}{ Low concentrated Microthrix sample } \\
\hline $\begin{array}{l}\text { Initial 16S concentration: } \\
\quad 1.11 \pm 0.1 \times 10^{4}\end{array}$ & / & $\mathrm{BD}$ & & \\
\hline \multirow{4}{*}{$\begin{array}{l}\text { Initial Microthrix } \\
\text { concentration: BD }\end{array}$} & 2661.81 & $2332.55 \pm 365.67$ & 2661.81 & $88 \%$ \\
\hline & 266.18 & $176.58 \pm 18.23$ & 266.18 & $66 \%$ \\
\hline & 26.62 & $21.52 \pm 4.72$ & 26.62 & $81 \%$ \\
\hline & 2.66 & $\mathrm{BD}$ & 2.66 & \\
\hline \multicolumn{5}{|c|}{ Moderately concentrated Microthrix sample } \\
\hline $\begin{array}{l}\text { Initial 16S concentration: } \\
\quad 2.56 \pm 0.8 \times 10^{5}\end{array}$ & / & $263.33 \pm 42.63$ & & \\
\hline Initial Microthrix & 2661.81 & $2304.03+187.37$ & 2924.81 & $79 \%$ \\
\hline concentration: & 266.18 & $427.67 \pm 71.27$ & 529.51 & $81 \%$ \\
\hline \multirow[t]{2}{*}{$263.33 \pm 42.63$} & 26.62 & $212.89 \pm 39.80$ & 289.95 & $73 \%$ \\
\hline & 2.66 & $172.51 \pm 21.18$ & 265.99 & $65 \%$ \\
\hline \multicolumn{5}{|c|}{ Highly concentrated Microthrix sample } \\
\hline $\begin{array}{l}\text { Initial 16S concentration: } \\
1.04 \pm 0.8 \times 10^{7}\end{array}$ & / & $1195.31 \pm 156.98$ & & \\
\hline \multirow{4}{*}{$\begin{array}{l}\text { Initial Microthrix } \\
\text { concentration: } \\
1195.31 \pm 156.98\end{array}$} & 2661.81 & $3287.72 \pm 687.45$ & 3857.12 & $85 \%$ \\
\hline & 266.18 & $1316.55 \pm 343.30$ & 1461.49 & $90 \%$ \\
\hline & 26.62 & $1106.74 \pm 120.09$ & 1221.93 & $90 \%$ \\
\hline & 2.66 & $1178.76 \pm 365.49$ & 1197.97 & $98 \%$ \\
\hline
\end{tabular}

yielded a lower concentration than expected. This effect was more pronounced for low concentrated samples. This is probably due to differences in amplification efficiency (clonal vs genomic DNA), primer/probe competition, etc. In addition, the spiking experiments revealed that there was no PCR inhibition (IPC $C_{t}$ values varied between 28.6 and 29.7), meaning that the IPC assay is functioning properly to assess inhibition. Spiking with high DNA concentrations (>10 ng DNA) reveals IPC $C_{t}$ values higher than 30 or IPC inhibition. This inhibition is due to competition between the internal control with the target, when this target is present in excess. Comparable results have been described by the IPC manufacturer and in the literature (Behets et al., 2007; Hallett and Bartholomew, 2009; McBeath et al., 2006). Similar values have been found by performing the same spiking experiment using a singleplex approach (i.e. Microthrix without IPC) (data not shown).

\subsection{Comparison between TaqMan, SYBR Green and microscopy}

Twenty-nine samples were processed and examined for the presence of M. parvicella and M. calida using the new described TaqMan assay, the previously described SYBR Green assay (Kaetzke et al., 2005) and conventional microscopy (Fig. 2). The results obtained with the TaqMan assay revealed no PCR inhibition in any sample as determined by the IPC controls ( $C_{t}$ values: $28.22 \pm 0.48$ ).

Microthrix was detected in all the samples (Fig. 2), which is not surprising as it is not only most frequently responsible for the problems of solid-liquid separation in bulking and foaming (Rossetti et al., 2005) but like many other filamentous species, it also forms an essential part of the floc structure (Sezgin et al., 1978).

In every case, the TaqMan assay detected more cells compared to the SYBR Green. Although the differences were small in most cases, some low concentrated samples showed a pronounced assay effect (samples 3, 17 and 24). The correlation of the Microthrix counts was examined by comparing the linear relationship between both detection methods on the 29 samples (Fig. 3). A clear positive correlation between the 2 assays was found $\left(R^{2}=0.85\right)$. Similar as in Fig. 2 , the highest variability is attributed to the samples with a low concentration of Microthrix. In contrast to what occurred in the SYBR Green-based quantification, the signal generation in the TaqMan assay was strictly specific due to cleavage of the TaqMan probe. Moreover the inter-assay variation of the SYBR assay was much higher than the TaqMan assay. NTC values 


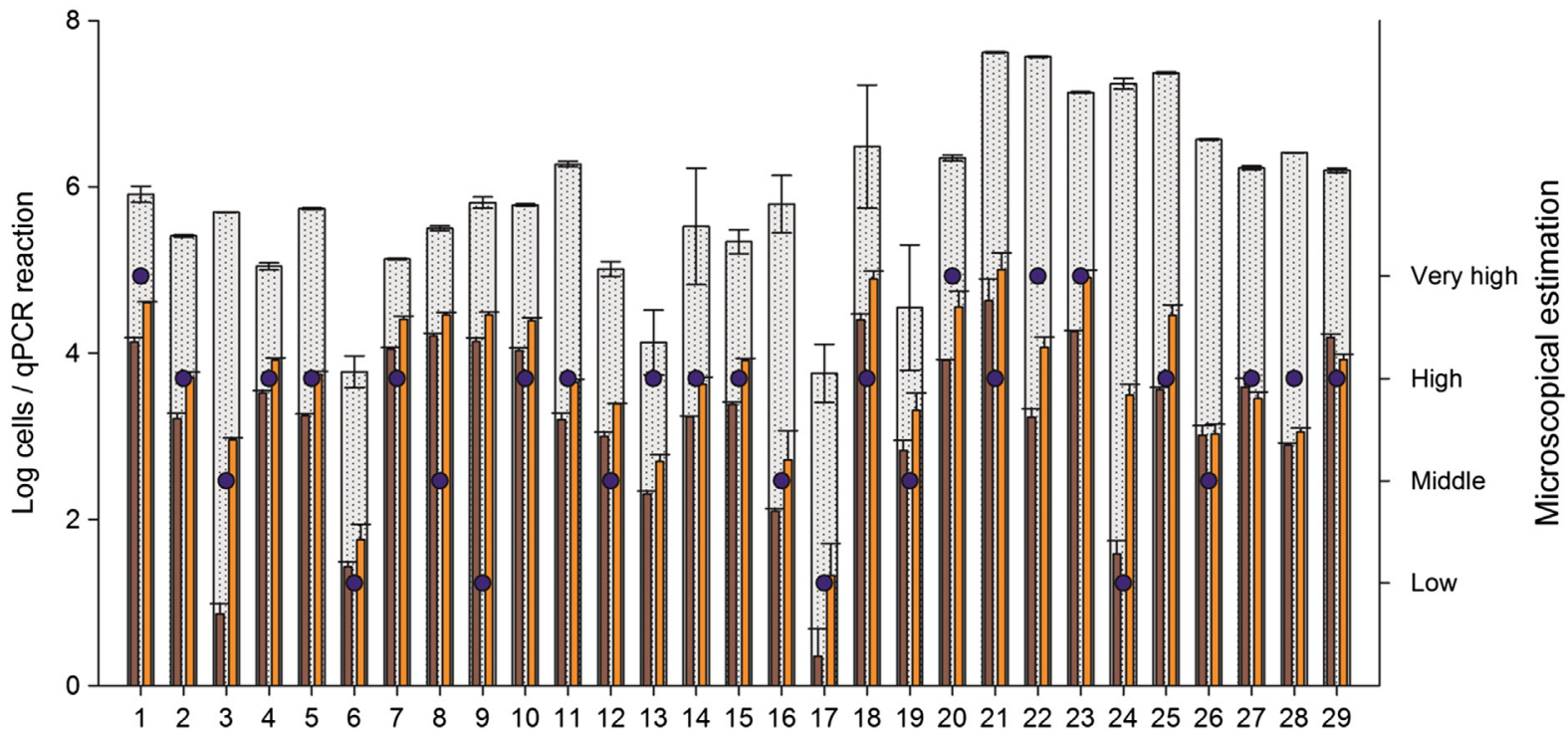

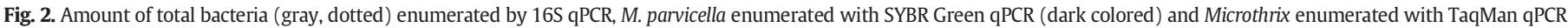

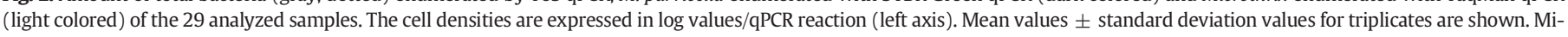

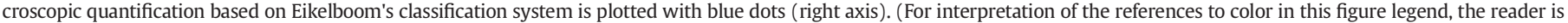
referred to the web version of this article.)

varied between $C_{t}$ values of $24.86-28.01$ and $32.25-38.58$ for the SYBR and TaqMan assay respectively. Also the melting temperatures in the SYBR assay varied between 83.8 and $85.0{ }^{\circ} \mathrm{C}$. Therefore, it is suggested that the TaqMan assay offers a more accurate quantification of low copy numbers compared to the SYBR Green based quantification.

The 29 samples were also compared with the microscopic data. In general, ten samples had a higher estimation using qPCR and 3 samples $(13,22,28)$ showed a higher Microthrix concentration using microscopy. Referring to the qPCR assays, ten samples showed a high similarity against the TaqMan assay, whereas 4 samples matched slightly better with the SYBR Green enumeration. Interestingly, in some cases the amount of total bacteria and Microthrix seems to be correlated (Figure 2, samples 6 and 17), yet a low correlation was found for both SYBR Green $\left(R^{2}=0.158\right)$ and TaqMan $\left(R^{2}=0.175\right)$ enumerations when related to the total bacteria counts. Therefore to avoid artificial values we plotted both enumerations on one graph instead of the Microthrix/total bacteria ratios like done by Kaetzke et al. (2005) and Kumari et al. (2009) (Fig. 2).

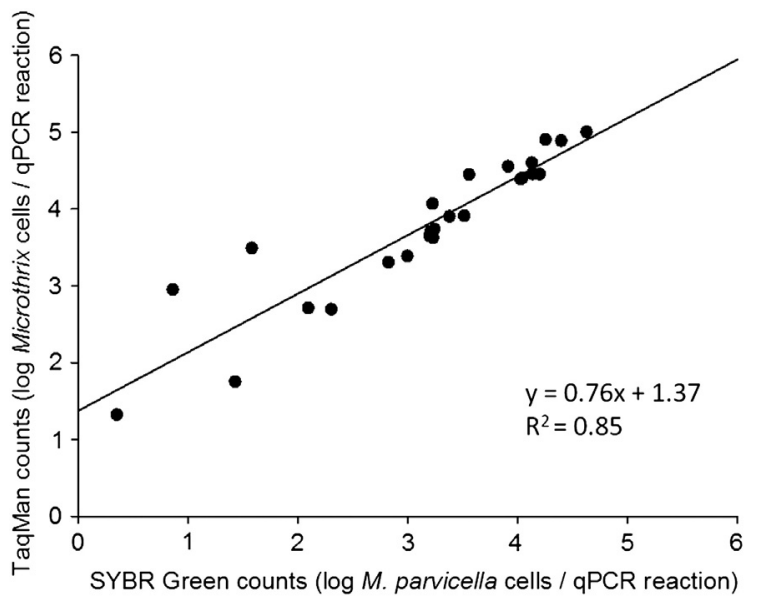

Fig. 3. Correlation between SYBR Green and TaqMan quantification for 29 sludge samples.
As mentioned above, the TaqMan assay was designed for both M. parvicella and $M$. calida morphotypes. Interestingly, the different morphotypes were found in sludge collected from the same sample (sample 27, Figs. 4E and F, 5B). One filament had a thickness in the range of $0.59-0.74 \mu \mathrm{m}$ and was identified as M. parvicella (Fig. 4A), whereas another filament was clearly thinner $(0.27-0.32 \mu \mathrm{m})$ and recognized as M. calida (Fig. 4B and C). Yet, no differences were found between the TaqMan and the SYBR Green assay for this particular sample, meaning that the differences are depending more on the sensitivity of the qPCR chemistry than on the primer specificity. Using FISH, Levantesi et al. (2006) found that the smaller filament diameter is not always a reliable distinctive character for in situ identification. Indeed, it was found that both thin and normal Microthrix filaments gave a positive signal with the Mpa-all-1410 probe suggesting that these unknown M. parvicella filaments were responsible for settling problems in several plants (Levantesi et al., 2006).

As the MPA-MIX probe was used in this study, no distinction could be made by FISH analysis (Fig. 5B). Therefore it is important to monitor different Microthrix morphotypes like suggested in this study. The fact that different morphotypes coexist in the same environment suggests that they are using different niches. Indeed, Levantesi et al. (2006) found that $M$. calida is able to grow at higher temperature and $\mathrm{pH}$ and no growth of $M$. calida is observed on $M$. parvicella specific medium (Slijkhuis, 1983a, 1983b). On the other hand pure culture studies indicate a lipase activity and a preferentially incorporation of long-chain fatty acids as an organic carbon and energy source, which is similar to M. parvicella.

Samples with a higher and lower estimation were further analyzed in detail. Samples 13, 22 and 28 had a lower estimation using qPCR. The IPC was never inhibited meaning that no PCR inhibitors were present. As different floc structures (compact (Fig. 5C) and diffuse (Fig. 5A and B)) were found, it can be excluded that the DNA extraction method was not able to degrade compact sludge flocs completely. Moreover, the DNA extraction method has been previously evaluated for different sludge types and should normally give an optimal DNA recovery (Vanysacker et al., 2010). Some samples were higher estimated using qPCR. However, for most of them the differences were rather small (samples 7, 10, 12, 18, 26) (Fig. 2). In contrast, sample 8 was 100 times higher estimated using qPCR. This sample had been subjected 

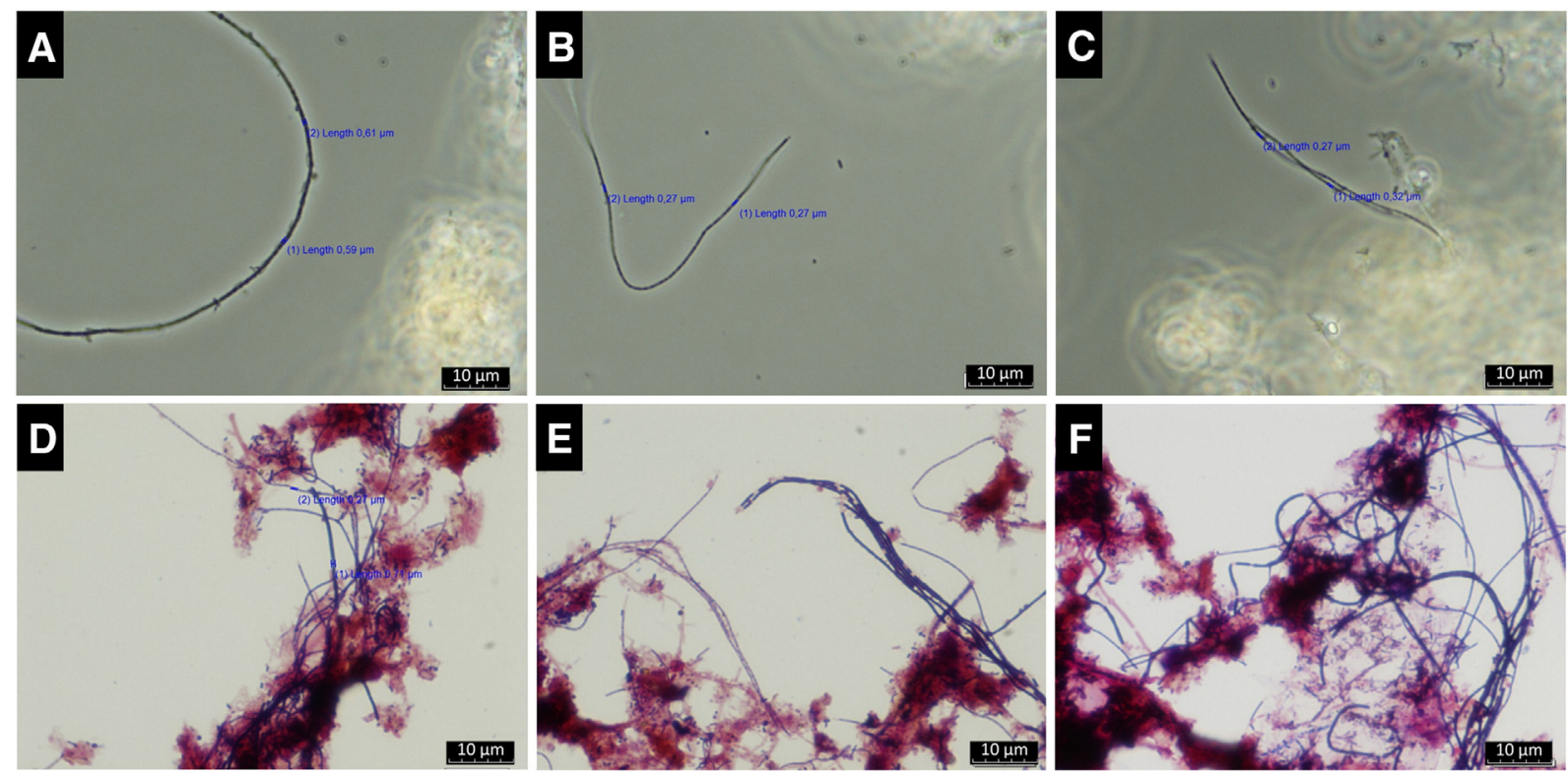

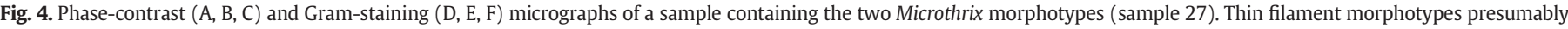
M. calida are shown in B and C. The M. parvicella morphotype is visible in A, D, E, and F and shows the occurrence of both filaments in the same sample.

to a PAX treatment. The exact effect of PAX on M. parvicella is not really clear, yet a change in surface properties and a decreased in fatty acid transport have been observed, followed by a decrease competitiveness of M. parvicella to the other bacteria (Hamit-Eminovski et al., 2010). Roels et al. (2002) observed a filament reduction only after 3 weeks PAX dosing whereas the floc structure started to improve after 10 to 15 days. In such situations Microthrix fragments are much shorter and difficult to detect with microscopy, but still present in the sample leading to a high qPCR enumeration. In addition, when the PAX treatment in such situations was stopped, a fast recovery of Microthrix and thus sludge bulking occurred (personal observation). These observations could explain why lower estimation of Microthrix was found using microscopy when compared to qPCR. A similar phenomenon has been observed for sample 21 (Fig. 2).

To exclude possible PCR inhibition by PAX for these two samples, an additional inhibition experiment was performed using different PAX-14 concentrations. In all cases, no PCR inhibition was found (IPC values in the range of 27.5-30.9, detailed data not shown). This means that PAX did not affect the qPCR reaction and rather differences between microscopy and qPCR were due to small, difficult to detect, Microthrix fragments.

The strong differences found in sample 9 remain unexplained (Fig. 2). As the amount of filament was low, no filament-identification could be done (Table 1). Samples 5, 9, 18, 25 and 28 were characterized by compact flocs (Fig. 5C), however this type of flocs did not lead systematically to a higher estimation by qPCR (samples 9,18 , and 25 versus 5 and 28). Also we could not explain the discrepancy between the SYBR Green and TaqMan results for sample 24 (Fig. 2). Some samples were distinct by clusters of Gram-positive cells, however these clusters did not affect the enumeration and the FISH staining (sample 26, Fig. 5A).

To summarize, this paper describes a method for the simultaneous detection of the M. parvicella and M. calida 16S rDNA gene and an IPC using the TaqMan chemistry. The additional TaqMan specificity afforded not only a higher accuracy compared to SYBR Green, but also the possibility of using multiple TaqMan probe and primer sets at the same time (Baldwin et al., 2003, 2008; Neretin et al., 2003). Moreover, using mulitplex PCR, simultaneous detection of total Bacteria or other problematic species such as Eikelboom's types (021N, 0675, 0041, 0961, 1701, 0914 and 0092), Thiothrix eikelboomii, Nostocoida limocola, and Gordonia amarae, etc. would be possible (Dumonceaux et al., 2006; Jenkins et al., 2004; Marrengane et al., 2011; Nielsen et al., 2009; Seviour et al., 1994; Vervaeren et al., 2005). However, the development of a multiplex qPCR using the same gene is difficult due to the competition for resources. Moreover, when one target is more abundant than another, unequal amplification will occur and the differences will be enhanced during each cycle, leading to artifact and misinterpretation of the data (Edwards and Gibbs, 1994). Furthermore, the use of the 16S rDNA gene, even though it is a highly homologous target sequence for practically all bacteria which can be used for detection (Barken et al., 2007; Mothershed and Whitney, 2006), can deliver some technical problems. Firstly, bacterial groups have different 165 rDNA copy numbers, ranging from 1 to 13 , making the comparison between distinct species difficult (Fogel et al., 1999). Secondly, the main problem for detection of bacterial DNA is the achievement of a high sensitivity along with a clear negative control. Up to now, this is an unresolved problem since the reagents used in the PCR process are contaminated with trace amounts of bacterial DNA, especially the Taq polymerase, where contamination originates from its production in bacterial cultures (Philipp et al., 2010). Therefore, the use of functional genes for multiplex PCR seems to be much easier. Recently, a genome announcement of $M$. parvicella has been published (Muller et al., 2012). Although the sequence assembly is not complete yet, some functional gene sequence will be soon available and the subsequent development of other quantification tools will be possible.

\section{Conclusions}

M. parvicella is one of the most common filamentous bacteria reported to be involved in bulking and foaming problems in activated sludge plants worldwide. Therefore an identification and quantification of this microorganism is a prerequisite for developing efficient control strategies to predict bulking and foaming events. The discussed duplex qPCR assay for the detection of Microthrix is a fast, accurate and sensitive surveillance tool with a much faster turnaround time than the classical microscopy. Making use of the TaqMan chemistry, a good correlation with an existing SYBR Green assay and conventional microscopy was demonstrated. Moreover, using TaqMan, a lower detection limit and lower NTC values were found compared to the SYBR Green assay. Although no PCR inhibition was found, the routine use of an IPC is 

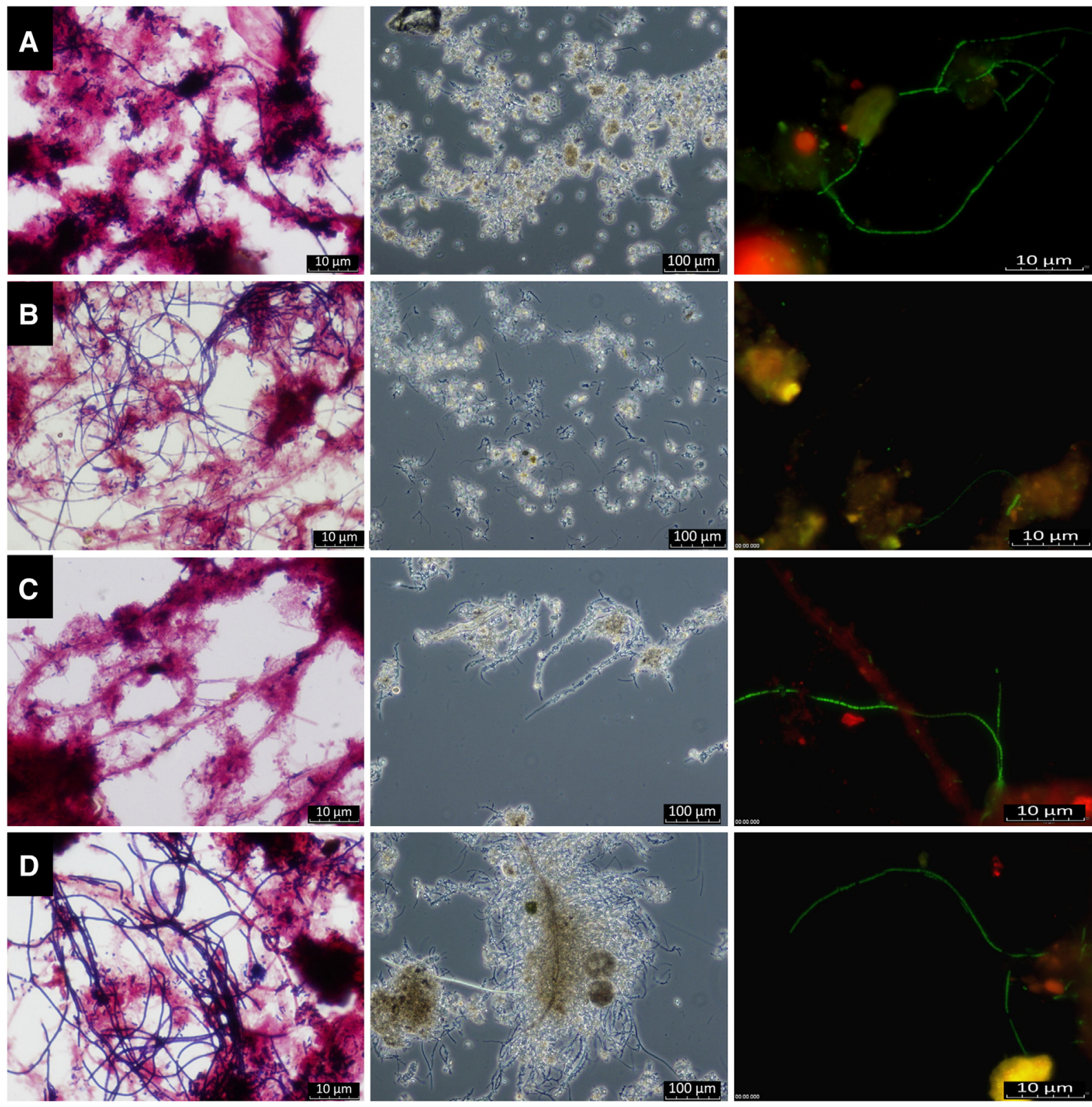

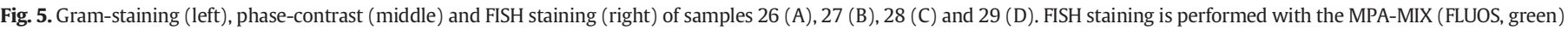

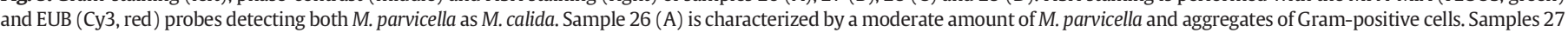
(B), 28 (C) and 29 (D) contain a high amount of M. parvicella.

strongly recommended to detect inhibitors during DNA amplification as it remains unpredictable whether environmental samples contain inhibiting substances.

\section{Acknowledgments}

This study was funded by the IDO/06/008 and IOF-KP/13/004 projects of the KU Leuven and an FWO project (G.0808.10N) of the Flemish government. Louise Vanysacker acknowledges the Fund for Scientific Research Flanders (FWO) for a PhD scholarship. The authors want to thank Bart Boerjan for proofreading the manuscript.

\section{References}

Adamse, A.D., 1970. Some characteristics of Arthrobacters from diary waste activated sludge. Water Res. 4, 797-803.
Amann, R.I., Krumholz, L., Stahl, D.A., 1990. Fluorescent-oligonucleotide probing of whole cells for determinative, phylogenetic, and environmental studies in microbiology. J. Bacteriol. 172, 762-770.

Baldwin, B.R., Nakatsu, C.H., Nies, L., 2003. Detection and enumeration of aromatic oxygenase genes by multiplex and real-time PCR. Appl. Environ. Microbiol. 69, 3350-3358.

Baldwin, B.R., Nakatsu, C.H., Nies, L., 2008. Enumeration of aromatic oxygenase genes to evaluate monitored natural attenuation at gasoline-contaminated sites. Water Res. 42, 723-731.

Barken, K.B., Haagensen, J.A.J., Tolker-Nielsen, T., 2007. Advances in nucleic acid-based diagnostics of bacterial infections. Clin. Chim. Acta 384, 1-11.

Behets, J., Declerck, P., Delaedt, Y., Verelst, L., Ollevier, F., 2007. A duplex real-time PCR assay for the quantitative detection of Naegleria fowleri in water samples. Water Res. 41, 118-126.

Blackall, L.L., Seviour, E.M., Cunningham, M.A., Seviour, R.J., Hugenholtz, P., 1995. "Microthrix parvicella" is a novel, deep branching member of the Actinomycetes subphylum. Syst. Appl. Microbiol. 17, 513-518.

Blackall, L.L., Stratton, H., Bradford, D., delDot, T., Sjorup, C., Seviour, E.M., Seviour, R.J., 1996. "Candidatus Microthrix parvicella", a filamentous bacterium from activated sludge sewage treatment plants. Int. J. Syst. Bacteriol. 46, 344-346.

Bradford, D., Christensson, C., Jakab, N., Blackall, L.L., 1998. Molecular biological methods to detect "Microthrix parvicella" and to determine its abundance in activated sludge. Water Sci. Technol. 37, 37-45. 
Daims, H., Taylor, M.W., Wagner, M., 2006. Wastewater treatment: a model system for microbial ecology. Trends Biotechnol. 24, 483-489.

de los Reyes, F.L., Rothauszky, D., Raskin, L., 2002. Microbial community structures in foaming and nonfoaming full-scale wastewater treatment plants. Water Environ. Res. 74, 437-449.

Dumonceaux, T.J., Hill, J.E., Pelletier, C.P., Paice, M.G., Van Kessel, A.G., Hemmingsen, S.M., 2006. Molecular characterization of microbial communities in Canadian pulp and paper activated sludge and quantification of a novel Thiothrix eikelboomii-like bulking filament. Can. J. Microbiol. 52, 494-500.

Edwards, M.C., Gibbs, R.A., 1994. Multiplex PCR: advantages, development, and applications. Genome Res. 3, S65-S75.

Eikelboom, D.H., 1975. Filamentous organisms observed in activated-sludge. Water Res. 9, 365-388.

Eikelboom, D.H., 2000. Process Control of Activated Sludge Plants by Microscopic Investigation. IWA Publishing, London, UK

Eikelboom, D.H., 2006. Identification and Control of Filamentous Microorganisms in Industrial Wastewater Treatment Plants. IWA Publishing, London, UK.

Eikelboom, D.H., Geurkink, B., 2000. Catalogue of filamentous microorganisms occurring in industrial activated sludge plants. TNO-MEP. Report R 2001, Apeldoorn, The Netherlands.

Eikelboom, D.H., Geurkink, B., 2002. Filamentous micro-organisms observed in industrial activated sludge plants. Water Sci. Technol. 46, 535-542.

Eikelboom, D.H., van Buijsen, H.J.J., 1983. Microscopic Sludge Investigation Manual. TNO, Delft, The Netherlands.

Erhart, R., Bradford, D., Seviour, R.J., Amann, R., Blackall, L.L., 1997. Development and use of fluorescent in situ hybridization probes for the detection and identification of "Microthrix parvicella" in activated sludge. Syst. Appl. Microbiol. 20, 310-318.

Fogel, G.B., Collins, C.R., Li, J., Brunk, C.F., 1999. Prokaryotic genome size and SSU rDNA copy number: estimation of microbial relative abundance from a mixed population. Microb. Ecol. 38, 93-113.

Gurr, E., 1965. The Rational Use of Dyes in Biology and General Staining Methods. Williams and Wilkins, London, UK.

Hallett, S.L., Bartholomew, J.L., 2009. Development and application of a duplex QPCR for river water samples to monitor the myxozoan parasite Parvicapsula minibicornis. Dis. Aquat. Org. 86, 39-50.

Hamit-Eminovski, J., Eskilsson, K., Arnebrant, T., 2010. Change in surface properties of Microthrix parvicella upon addition of polyaluminium chloride as characterized by atomic force microscopy. Biofouling 26, 323-331.

Hartman, L.J., Coyne, S.R., Norwood, D.A., 2005. Development of a novel internal positive control for Taqman ${ }^{\circledR}$ based assays. Mol. Cell. Probes 19, 51-59.

Jenkins, D., Richard, M.G., Daigger, G.T., 2004. Manual on the Causes and Control of Activated Sludge Bulking, Foaming, and Other Solids Separation Problems. IWA Publishing, London, UK.

Kaetzke, A., Jentzsch, D., Eschrich, K., 2005. Quantification of Microthrix parvicella in activated sludge bacterial communities by real-time PCR. Lett. Appl. Microbiol. 40, 207-211.

Klappenbach, J.A., Saxman, P.R., Cole, J.R., Schmidt, T.M., 2001. rrndb: the ribosomal RNA operon copy number database. Nucleic Acids Res. 29, 181-184.

Kumari, S.K.S., Marrengane, Z., Bux, F., 2009. Application of quantitative RT-PCR to determine the distribution of Microthrix parvicella in full-scale activated sludge treatment systems. Appl. Microbiol. Biotechnol. 83, 1135-1141.

Levantesi, C., Rossetti, S., Thelen, K., Kragelund, C., Krooneman, J., Eikelboom, D., Nielsen, P.H., Tandoi, V., 2006. Phylogeny, physiology and distribution of 'Candidatus Microthrix calida', a new Microthrix species isolated from industrial activated sludge wastewater treatment plants. Environ. Microbiol. 8, 1552-1563.

Livak, K.J., Flood, S.J.A., Marmaro, J., Giusti, W., Deetz, K., 1995. Oligonucleotides with fluorescent dyes at opposite ends provide a quenched probe system useful for detecting PCR product and nucleic-acid hybridization. PCR-Methods Appl. 4, 357-362.

Marrengane, Z., Kumar, S.K.S., Pillay, L., Bux, F., 2011. Rapid quantification and analysis of genetic diversity among Gordonia populations in foaming activated sludge plants. J. Basic Microbiol. 51, 415-423.

Martins, A.M.P., Pagilla, K., Heijnen, J.J., van Loosdrecht, M.C.M., 2004. Filamentous bulking sludge-a critical review. Water Res. 38, 793-817.

McBeath, A.J.A., Penston, M.J., Snow, M., Cook, P.F., Bricknell, I.R., Cunningham, C.O., 2006 Development and application of real-time PCR for specific detection of Lepeophtheirus salmonis and Caligus elongatus larvae in Scottish plankton samples. Dis. Aquat. Org. 73, 141-150.

Mothershed, E.A., Whitney, A.M., 2006. Nucleic acid-based methods for the detection of bacterial pathogens: present and future considerations for the clinical laboratory. Clin. Chim. Acta 363, 206-220.

Muller, E.E.L., Pinel, N., Gillece, J.D., Schupp, J.M., Price, L.B., Engelthaler, D.M., Levantesi, C., Tandoi, V., Luong, K., Baliga, N.S., Korlach, J., Keim, P.S., Wilmes, P., 2012. Genome sequence of "Candidatus Microthrix parvicella" Bio17-1, a long-chain-fatty-acidaccumulating filamentous actinobacterium from a biological wastewater treatment plant. J. Bacteriol. 194, 6670-6671.
Neretin, L.N., Schippers, A., Pernthaler, A., Hamann, K., Amann, R., Jorgensen, B.B. 2003. Quantification of dissimilatory (bi)sulphite reductase gene expression in Desulfobacterium autotrophicum using real-time RT-PCR. Environ. Microbiol. 5 660-671.

Nielsen, P.H., 2009. Protocol for fluorescent in situ hybridization (FISH) with rRNAtargeted oligonucleotides. In: Nielsen, P.H., Daims, H., Lemmer, H. (Eds.), FISH Handbook for Biological Wastewater Treatment. IWA Publishing, London, UK.

Nielsen, P.H., Kragelund, C., Nielsen, J.L., Tiro, S., Lebek, M., Rosenwinkel, K.-H., Gessesse, A., 2005. Control of Microthrix parvicella in activated sludge plants by dosage of polyaluminium salts: possible mechanisms. Acta Hydrochim. Hydrobiol. 33 255-261.

Nielsen, P.H., Kragelund, C., Seviour, R.J., Nielsen, J.L., 2009. Identity and ecophysiology of filamentous bacteria in activated sludge. FEMS Microbiol. Rev. 33 969-998.

Oerther, D.B., de los Reyes Iii, F.L., de los Reyes, M.F., Raskin, L., 2001. Quantifying filamentous microorganisms in activated sludge before, during, and after an incident of foaming by oligonucleotide probe hybridizations and antibody staining. Water Res. $35,3325-3336$.

Paris, S., Lind, G., Lemmer, H., Wilderer, P.A., 2005. Dosing aluminum chloride to control Microthrix parvicella. Acta Hydrochim. Hydrobiol. 33, 247-254.

Philipp, S., Huemer, H.P., Irschick, E.U., Gassner, C., 2010. Obstacles of multiplex real-time PCR for bacterial 16S rDNA: primer specificity and DNA decontamination of Taq polymerase. Transfus. Med. Hemother. 37, 21-28.

Radstrom, P., Knutsson, R., Wolffs, P., Lovenklev, M., Lofstrom, C., 2004. Pre-PCR processing -strategies to generate PCR-compatible samples. Mol. Biotechnol. 26, 133-146.

Roels, T., Dauwe, F., Van Damme, S., De Wilde, K., Roelandt, F., 2002. The influence of PAX14 on activated sludge systems and in particular on Microthrix parvicella. Water Sci. Technol. 46, 487-490.

Rossetti, S., Christensson, C., Blackall, L.L., Tandoi, V., 1997. Phenotypic and phylogenetic description of an Italian isolate of "Microthrix parvicella". J. Appl. Microbiol. 82 405-410.

Rossetti, S., Tomei, M.C., Nielsen, P.H., Tandoi, V., 2005. “Microthrix parvicella”, a filamentous bacterium causing bulking and foaming in activated sludge systems: a review of current knowledge. FEMS Microbiol. Rev. 29, 49-64.

Seviour, E.M., Williams, C., Degrey, B., Soddell, J.A., Seviour, R.J., Lindrea, K.C., 1994. Studies on filamentous bacteria from Australian activated-sludge plants. Water Res. 28, 2335-2342.

Sezgin, M., Jenkins, D., Parker, D.S., 1978. A unified theory of filamentous activated sludge bulking. J. Water Pollut. Control Fed. 362-381.

Slijkhuis, H., 1983a. Microthrix parvicella, a filamentous bacterium isolated from activatedsludge-cultivation in a chemically defined medium. Appl. Environ. Microbiol. 46, 832-839.

Slijkhuis, H., 1983b. The Physiology of the Filamentous Bacterium M. parvicella. Ph.D. thesis Agriculture College of Wageningen, The Netherlands.

Stark, P.C., Mullen, K.I., Banton, K., Russotti, R., Soran, D., Kuske, C.R., 2000. Pre-PCR DNA quantitation of soil and sediment samples: method development and instrument design. Soil Biol. Biochem. 32, 1101-1110.

Stults, J.R., Snoeyenbos-West, O., Methe, B., Lovley, D.R., Chandler, D.P., 2001. Application of the $5^{\prime}$ fluorogenic exonuclease assay (TaqMan) for quantitative ribosomal DNA and rRNA analysis in sediments. Appl. Environ. Microbiol. 67, 2781-2789.

Suzuki, M.T., Taylor, L.T., DeLong, E.F., 2000. Quantitative analysis of small-subunit rRNA genes in mixed microbial populations via 5'-nuclease assays. Appl. Environ. Microbiol. 66, 4605-4614.

Tandoi, V., Rossetti, S., Blackall, L.L., Majone, M., 1998. Some physiological properties of an Italian isolate of "Microthrix parvicella". Water Sci. Technol. 37, 1-8.

Van Veen, W.L., 1973. Bacteriology of activated sludge, in particular the filamentous bacteria. Antonie Leeuwenhoek 39, 189-205.

Vanysacker, L., Declerck, S.A.J., Hellemans, B., De Meester, L., Vankelecom, I., Declerck, P., 2010. Bacterial community analysis of activated sludge: an evaluation of four commonly used DNA extraction methods. Appl. Microbiol. Biotechnol. 88, 299-307.

Vervaeren, H., De Wilde, K., Matthys, J., Boon, N., Raskin, L., Verstraete, W., 2005 Quantification of an Eikelboom type 021N bulking event with fluorescence in situ hybridization and real-time PCR. Appl. Microbiol. Biotechnol. 68, 695-704.

Wanner, J., 1994. Activated Sludge Bulking and Foaming Control. Technomic Publishing Co., Lancaster, UK.

Welti, M., Jaton, K., Altwegg, M., Sahli, R., Wenger, A., Bille, J., 2003. Development of a multiplex real-time quantitative PCR assay to detect Chlamydia pneumoniae, Legionella pneumophila and Mycoplasma pneumoniae in respiratory tract secretions. Diagn. Microbiol. Infect. Dis. 45, 85-95.

Westlund, A.D., Hagland, E., Rothman, M., 1998. Foaming in anaerobic digesters caused by Microthrix parvicella. Water Sci. Technol. 37, 51-55.

Wilson, I.G., 1997. Inhibition and facilitation of nucleic acid amplification. Appl. Environ. Microbiol. 63, 3741-3751. 